\title{
Ethnic variations in pathways into early intervention services for psychosis ${ }^{\dagger}$
}

Sharif Ghali, Helen L. Fisher, John Joyce, Barnaby Major, Lorna Hobbs, Sujata Soni,

Brock Chisholm, Nikola Rahaman, Peggy Papada, Jo Lawrence, Sally Bloy, Karl Marlowe, Katherine J. Aitchison, Paddy Power and Sonia Johnson

\section{Background}

Ethnic variations have previously been identified in the duration of untreated psychosis (DUP) and pathways into psychiatric services. These have not been examined in the context of early intervention services, which may alter these trajectories.

\section{Aims \\ To explore ethnic differences in the nature and duration of pathways into early intervention services.}

\section{Method}

In a naturalistic cohort study, data were collected for 1024 individuals with psychotic disorders accepted for case management by eight London early intervention services.

\section{Results}

Duration of untreated psychosis was prolonged in the White British group compared with most other ethnic groups. White British individuals were more likely to make contact with their general practitioner and less likely to be seen within emergency medical services. All Black patient groups were more likely than their White British counterparts to experience involvement of criminal justice agencies.

\section{Conclusions}

Variations continue to exist in how and when individuals from different ethnic groups access early intervention services. These may account for disparities in DUP.

\section{Declaration of interest}

None.
Over recent years, early intervention services have been introduced throughout the UK for young people presenting for the first time with a psychotic disorder. A central tenet of the early intervention services model is early detection of psychosis and initiation of pharmacotherapy. ${ }^{1}$ This is supported by a substantial body of evidence confirming an association between duration of untreated psychosis (DUP) and poorer outcome ${ }^{2}$ and driven by policy directives aimed at reducing these delays. ${ }^{3}$ Although DUP represents the time taken to obtain appropriate treatment, the nature of the journey through which individuals and their carers seek help and make contact with services has also attracted much interest. These two concepts are intrinsically bound.

Evidence exploring DUP in different ethnic groups has pointed towards greater treatment delays in Black and minority ethnic (BME) groups in North America. ${ }^{4,5}$ This disparity has not been seen in the UK, and this is perhaps contradictory to assumptions seen in the academic literature and policy documents that individuals from these groups might delay help-seeking compared with White individuals. ${ }^{6}$ With regard to ethnic differences in the nature of the pathway into services in firstepisode psychosis, there has been a lack of consistent findings. This may be explained by methodological limitations such as small sample size, and international and inter-regional differences in clinical, societal and healthcare factors. The Aetiology and Ethnicity in Schizophrenia and Other Psychoses (ÆSOP) study identified more adverse pathways to traditional mental healthcare in BME groups ${ }^{7}$ and this is a prevalent conclusion from research in the wider mental health context. ${ }^{8}$

Although the majority of this research was published over the past decade, there have been no UK studies, and internationally only one from Canada, ${ }^{9}$ examining this in the context of early intervention services. This Canadian study found no ethnic differences in DUP and few disparities in how services are

†See editorial, pp. 249-250, and invited commentary, pp. 284-285, this issue. accessed. Following the introduction of this new service model, a greater understanding of how different groups interact with healthcare systems may allow us to more effectively target interventions aimed at reducing DUP and to improve pathways to care.

Using data from a large pan-London naturalistic epidemiological cohort, we sought to examine ethnic differences in the nature and time frames of pathways into early intervention services. Variations in two measures of DUP and three common contacts within the pathway into services were explored and consideration was given to whether these were independent of social, demographic and clinical characteristics.

\section{Method}

This naturalistic study comprised eight established early intervention services, serving a combined population of 2.4 million across the London boroughs of Brent, Camden \& Islington, Croydon (COAST), Hackney (EQUIP), Kensington, Chelsea \& Westminster (KCW), Lewisham, Tower Hamlets (THEIS) and Wandsworth (ETHOS). The study aimed to include all new consecutive referrals to early intervention services taken on for case management from 2003 until 2009, although for pragmatic reasons this was not uniformly performed across the teams. Data collection was restricted to certain teams in the early stages and within some fledgling services the entire catchment area was not initially covered, resulting in available data for only a proportion of eligible patients. However, from 2006 early intervention services were more broadly implemented and at least basic data were collected for all accepted patients. The date of referral into early intervention services for the first patient included from each team was as follows: Camden \& Islington, 2 October 2003; Lewisham, 3 June 2004; EQUIP, 1 December 2004; THEIS, 7 December 2004; ETHOS, 6 January 2005; COAST, 16 February 2005; KCW, 20 June 2005; and Brent, 10 November 2005. Inclusion criteria were service-dependent and not standardised, although the eight participating early intervention service teams followed similar 
principles when assessing suitability for entry into the service: namely, individuals with a recent first presentation to mental health services for affective or non-affective psychosis, aged 18 35 years and resident in the relevant London borough.

\section{Data collection}

Data were collected using MiData (minimum data-set), an audit tool initially piloted in Camden \& Islington early intervention services and adopted by the London Early Intervention Research Network in 2004. ${ }^{10}$ The tool contains standardised measures chosen for their coverage of key areas, feasibility, brevity and established use within the literature for this patient group. Data were collected and entered by clinicians, most commonly care coordinators, into the computerised database, following the completion of a comprehensive routine clinical assessment at the point of entry into early intervention services. Clinicians completing the tool had access to information from clinical records and collateral history. All clinicians were provided with training in the assessment tools and given regular refresher sessions.

\section{Sociodemographic information}

These data were collected using standardised questions and, for the purposes of the study, used as continuous and categorical variables with definitions as follows: age in years at entry to early intervention services (continuous); gender (male or female); country of birth (born in UK or outside of UK); marital status (married/cohabiting or single/divorced/separated/widowed); has children (yes or no); current living arrangement (living alone or living with others); social support (contact with others who are a source of support and show a positive interest in the individual's psychological well-being or limited/no social support); ever sought asylum (yes or no); employment status (employed/student or unemployed/homemaker/other); and educational level (no qualifications/GCSEs or A-levels/high school diploma taken at 17 or 18 in another country/GNVQ/higher qualification).

\section{Duration of untreated psychosis}

This was recorded using a shortened version of the Nottingham Onset Schedule (NOS-DUP). ${ }^{11}$ This scale has good psychometric properties and all clinicians demonstrated satisfactory interrater reliability before completing the assessment. The start of DUP was the date of emergence of a first psychotic symptom, usually hallucination, delusion or thought disorder, which met criteria for a score of four or more on the Positive and Negative Syndrome Scale (PANSS). ${ }^{12}$ Clinicians received intensive training on the PANSS rating system and were required to demonstrate high reliability with expert raters. As an end-point, the primary outcome variable, treatment DUP, refers to the date the individual commenced regular prescribed antipsychotic medication and thereafter was believed to be adherent for at least $75 \%$ of the time during the subsequent month. Service DUP was defined as ending on the date of referral to an early intervention service.

\section{Pathway contacts}

MiData's pathway to care tool contains information regarding contact points prior to referral to any mental health service. This refers only to contacts occurring in relation to psychosis. The three most commonly used contacts were examined in this study, namely general practitioner (GP), emergency medical services (primarily accident and emergency departments, and walk-in centres) and criminal justice agencies (police, prison or probation services) (see Fisher et al, ${ }^{10}$ for further details).

\section{Ethnicity}

MiData recorded ethnicity largely in accordance with the Census of Population for England \& Wales performed by the Office for National Statistics. ${ }^{13}$ Individuals were initially assigned to one of 19 categories. These were subsequently distilled to seven ethnic groups, primarily to ensure that group size was sufficient to afford statistical power for analysis. In the classification of Black groups, a distinction was made between first- and second-generation (Black British) individuals, with the former group being further subdivided into those born in the Caribbean or in Africa. This was considered an important distinction, as pathways to care have previously been found to differ between Black Caribbean and Black African patients with psychosis. ${ }^{7}$ The ethnic groups included in the analysis were: White British, White Other (including White Irish), South Asian (Bangladeshi, Pakistani, Indian), Black British (Black and born in the UK), Black Caribbean (Black and born in the Caribbean) and Black African (Black and born in Africa). All other ethnic groups were excluded from analysis.

\section{Clinical instruments}

Incorporated into the assessment were several validated clinical instruments providing information about psychotic and manic symptomatology, level of psychosocial functioning and substance misuse.

(a) The PANSS ${ }^{12}$ assesses severity of positive (maximum score 49) and negative (maximum score 49) psychotic symptoms along with general psychopathology (maximum score 112). Lack of insight was thought to be particularly relevant and therefore this item was dichotomised into none to mild (scores of 1-3) or moderate to extreme (scores of 4-7).

(b) The Young Mania Rating Scale (YMRS) ${ }^{14}$ covers manic symptoms (maximum score 60). Individuals scoring 20 or more were defined as clinically manic in accordance with Young et al. ${ }^{14}$

(c) The Global Assessment of Functioning (GAF) ${ }^{15}$ assesses level of symptomatic, social and vocational disability/functioning.

(d) In the Combined Alcohol Use Scale and Drug Use Scale ${ }^{16}$ each substance is rated for use in the past 6 months on a four-point scale (no use, occasional use, misuse or dependence) and for any lifetime use (yes or no). Here, substance misuse was defined as present if the individual was rated as misusing or dependent on alcohol or any illegal drug in the preceding 6 months.

\section{Analysis}

Multicentre ethical approval to merge anonymised MiData datasets was obtained from the Wandsworth Research Ethics Committee and written consent was provided by each participating team for their data to be included. Data from the eight early intervention services were collected and merged into SPSS (Statistical Package for Social Sciences, version 17.0 for Windows). Both measures of DUP demonstrated a significant degree of positive skewness, and so a natural logarithm transformation was applied allowing the application of parametric tests. The relationship between DUP and ethnicity was explored, initially using analysis of variance (ANOVA) and then by multiple regression analysis controlling for potential confounding factors. Sociodemographic and clinical covariates were selected for inclusion in the regression model if 
they were shown to be independently associated with either DUP or ethnicity at the $P<0.1$ level. A third-step analysis was then performed whereby pathway contacts were included into the model.

The relationship between the use of the three pathway contacts and ethnicity was explored using chi-squared tests and subsequently binary logistic regression analysis. The same method was applied to select covariates for inclusion in the regression model.

\section{Missing data}

Sociodemographic and clinical differences were explored between those with and without completed data for the primary outcome variable, treatment DUP, using independent samples $t$-tests and chi-squared tests. For the multivariate analysis, missing values for all confounders were replaced using multiple imputation. This method, performed using SPSS version 17.0, uses existing data to generate five different data-sets on which regression analyses might be applied and pools the results.

\section{Results}

Data were collected for 1024 individuals from eight early intervention services. Of these, 75.7\% $(n=775)$ fell within the following ethnic groups: White British $(n=215)$, White Other $(n=123)$, South Asian $(n=90)$, Black British $(n=169)$, Black Caribbean $(n=28)$ or Black African $(n=150)$. This sample comprised 500 males $(64.5 \%)$ and the mean age at entry to early intervention services was 23.7 years (s.d. $=4.7$; range $13-35$ ). Differing rates of data completeness were seen among the variables, ranging from $60 \%$ (PANSS score) to $99.2 \%$ (gender). Data regarding the primary outcome measure, treatment DUP, was available in $68 \%(n=528)$ of cases. For individual teams, this completion rate was as follows: COAST 86\%; Brent $86 \%$; Lewisham 73\%; Camden \& Islington 70\%; KCW 69\%; ETHOS 63\%; EQUIP 47\%; and THEIS 38\%. No statistically significant differences in sociodemographic or clinical factors existed between individuals with and without these data.

\section{Sample characteristics}

Sociodemographic and clinical characteristics of the sample are summarised by ethnicity in Table 1 . Within the sample analysed $(n=775)$, the median treatment DUP was 11.5 weeks (range 0839 ) and the mean was 39.8 weeks (s.d.=97.2). For service DUP, the median value was 16.0 weeks (range 0-840) and mean was 50.0 weeks $($ s.d. $=102.5)$. Forty-six per cent $(n=310)$ of individuals made contact with a GP on the pathway into early intervention services. Emergency medical services were used by $45 \%$, and $24 \%$ of individuals passed through criminal justice agencies prior to accessing early intervention services.

Statistically significant differences were noted between ethnic groups with respect to age, marital status, living arrangements, educational level, substance misuse and insight. Therefore, these variables were included as potential confounders in the regression analyses.

\section{Ethnicity and DUP}

The results of uni- and multivariate analyses exploring the association between ethnicity and both measures of DUP are presented in Table 2. Ethnicity was overall significantly associated with service DUP $(P<0.001)$, but the association with treatment DUP did not quite reach conventional levels of statistical significance $(P=0.095)$. Multiple comparison tests show that compared with the White British group, South Asian, Black British and Black African patients tended to experience shorter treatment DUP. All but the Black Caribbean group experienced significantly briefer service DUP than White British patients.

Following inclusion of covariates demonstrated to be associated with ethnicity or DUP into the regression model (results not shown), there was little alteration to these associations. Further addition of the three pathway contact variables into the model resulted in an overall reduction of the statistical magnitude of difference identified between ethnic groups.

\section{Ethnicity and pathway contacts}

The results of analyses examining ethnic variation in the use of pathway contacts can be seen in Table 3. The involvement of each

\begin{tabular}{|c|c|c|c|c|c|c|c|c|c|}
\hline & $\begin{array}{l}\text { Total } \\
\text { sample } \\
(n=775)\end{array}$ & $\begin{array}{l}\text { White } \\
\text { British } \\
(n=215)\end{array}$ & $\begin{array}{l}\text { White } \\
\text { Other } \\
(n=123)\end{array}$ & $\begin{array}{l}\text { South } \\
\text { Asian } \\
(n=90)\end{array}$ & $\begin{array}{c}\text { Black } \\
\text { British } \\
(n=169)\end{array}$ & $\begin{array}{c}\text { Black } \\
\text { Caribbean } \\
(n=28)\end{array}$ & $\begin{array}{c}\text { Black } \\
\text { African } \\
(n=150)\end{array}$ & $\begin{array}{c}\text { Test } \\
\text { statistic }\end{array}$ & $P$ \\
\hline Age, years: mean & 23.7 & 23.4 & 24.3 & 23.4 & 22.7 & 24.7 & 24.5 & $F=3.2$ & 0.007 \\
\hline Male, $n(\%)$ & $500(65.0)$ & $152(70.7)$ & $71(59.7)$ & $56(62.9)$ & $113(66.9)$ & $14(50.0)$ & $94(63.1)$ & $\chi^{2}=8.0$ & 0.16 \\
\hline Married/cohabiting, n (\%) & $52(7.2)$ & $12(6.0)$ & $11(10.2)$ & $11(13.1)$ & $1(0.6)$ & $4(14.3)$ & $13(8.9)$ & $\chi^{2}=19.3$ & 0.002 \\
\hline UK-born, $n(\%)$ & $472(60.9)$ & $215(100)$ & $26(21.1)$ & $62(68.9)$ & $169(100)$ & $0(0)$ & $0(0)$ & $\chi^{2}=608$ & $<0.001$ \\
\hline Living alone, $n$ (\%) & $137(20.5)$ & $30(16.6)$ & $18(18.4)$ & $9(11.0)$ & $41(27.2)$ & $6(26.1)$ & $33(24.6)$ & $\chi^{2}=12.5$ & 0.029 \\
\hline Children, $n(\%)$ & $93(12.3)$ & $20(9.6)$ & $11(9.1)$ & $11(12.6)$ & $20(12.4)$ & $7(25.9)$ & $24(16.0)$ & $\chi^{2}=9.2$ & 0.10 \\
\hline Employed or studying, $n(\%)$ & $222(31.9)$ & $65(33.5)$ & $36(34.6)$ & $22(27.5)$ & $46(30.7)$ & $9(36.0)$ & $44(31.0)$ & $\chi^{2}=1.65$ & 0.90 \\
\hline $\begin{array}{l}\text { Educational level, A-level } \\
\text { or above: } n(\%)\end{array}$ & $297(44.1)$ & $83(44.4)$ & $52(54.2)$ & $35(43.8)$ & $49(32.9)$ & $6(26.1)$ & $72(51.8)$ & $\chi^{2}=17.9$ & 0.003 \\
\hline Good social support, $n(\%)$ & $522(74.7)$ & $149(72.9)$ & $83(78.3)$ & $59(73.8)$ & $122(80.8)$ & $17(65.4)$ & $101(70.1)$ & $\chi^{2}=6.83$ & 0.23 \\
\hline Ever sought asylum, $n$ (\%) & $105(16.3)$ & $1(0.5)$ & $25(24.8)$ & $5(8.1)$ & $2(1.2)$ & $12(70.6)$ & $60(69.0)$ & $\chi^{2}=289$ & $<0.001$ \\
\hline Substance misuse, $n(\%)$ & $160(32.1)$ & $52(43.3)$ & $29(33.0)$ & $14(22.2)$ & $39(35.1)$ & $3(17.6)$ & $23(23.2)$ & $\chi^{2}=15.5$ & 0.009 \\
\hline PANSS total score, mean & 68.4 & 65.7 & 71.9 & 69.1 & 67.8 & 59.1 & 71.2 & $F=1.3$ & 0.28 \\
\hline $\begin{array}{l}\text { Lack of insight (moderate } \\
\text { to extreme), } n(\%)\end{array}$ & $218(42.9)$ & $47(33.8)$ & $36(48.0)$ & $27(42.9)$ & $46(42.2)$ & $5(31.3)$ & $57(53.8)$ & $\chi^{2}=11.5$ & 0.042 \\
\hline YMRS score $>20, n(\%)$ & $74(13.7)$ & $13(9.2)$ & $15(17.4)$ & $13(19.4)$ & $14(12.1)$ & $1(5.9)$ & $18(16.2)$ & $\chi^{2}=7.1$ & 0.22 \\
\hline GAF-d score, mean & 51.3 & 52.9 & 47.1 & 52.5 & 51.3 & 56.3 & 51.3 & $F=1.5$ & 0.20 \\
\hline
\end{tabular}




\begin{tabular}{|c|c|c|c|c|c|c|c|c|}
\hline & \multicolumn{4}{|c|}{ Treatment duration of untreated psychosis ${ }^{a}$} & \multicolumn{4}{|c|}{ Service duration of untreated psychosis ${ }^{b}$} \\
\hline & Median, days & IQR, days & $\begin{array}{c}\text { Mean } \\
\text { difference, nlog }\end{array}$ & $P^{\mathrm{c}}$ & Median, days & IQR, days & $\begin{array}{c}\text { Mean } \\
\text { difference, nlog }\end{array}$ & $P^{\mathrm{c}}$ \\
\hline White British & 113 & 345 & & & 215 & 512 & & \\
\hline White Other & 72 & 198 & 0.22 & $\begin{array}{l}0.38 \\
0.055^{\mathrm{d}} \\
0.13^{\mathrm{e}}\end{array}$ & 103 & 203 & 0.76 & $\begin{array}{l}0.001 \\
0.002^{f} \\
0.006^{g}\end{array}$ \\
\hline South Asian & 60 & 164 & 0.67 & $\begin{array}{l}0.020 \\
0.003^{\mathrm{d}} \\
0.004^{\mathrm{e}}\end{array}$ & 83 & 193 & 1.01 & $\begin{array}{l}<0.001 \\
<0.001^{\ddagger} \\
<0.001\end{array}$ \\
\hline Black British & 98 & 182 & 0.45 & $\begin{array}{l}0.049 \\
0.051^{\mathrm{d}} \\
0.16^{\mathrm{e}}\end{array}$ & 122 & 255 & 0.45 & $\begin{array}{l}0.025 \\
0.021^{\dagger} \\
0.17^{g}\end{array}$ \\
\hline Black Caribbean & 55 & 236 & 0.82 & $\begin{array}{l}0.058 \\
0.013^{\mathrm{d}} \\
0.065^{\mathrm{e}}\end{array}$ & 79 & 296 & 0.58 & $\begin{array}{l}0.14 \\
0.055^{f} \\
0.19^{g}\end{array}$ \\
\hline Black African & 57 & 155 & 0.50 & $\begin{array}{l}0.038 \\
0.010^{\mathrm{d}} \\
0.010^{\mathrm{e}}\end{array}$ & 72 & 190 & 0.82 & $\begin{array}{c}<0.001 \\
0.005^{f} \\
0.004^{g}\end{array}$ \\
\hline \multicolumn{9}{|c|}{$\begin{array}{l}\text { IQR, interquartile range; nlog, natural logarithm. } \\
\text { a. } F=1.89 \text {, d.f. }=5 \text {, between-groups ANOVA. } \\
\text { b. F=5.08, d.f. }=5 \text {, between-groups ANOVA. } \\
\text { c. Derived from least significant difference post hoc comparisons. } \\
\text { d. Adjusted for age, gender, marital status, having children, UK birth, living arrangements, educational and employment status, social support, asylum status, substance misuse, } \\
\text { Positive and Negative Syndrome Scale total score and Global Assessment of Functioning disability score. } \\
\text { e. Adjusted as in footnote d, plus use of three pathway contacts. } \\
\text { f. Adjusted for age, gender, marital status, UK birth, living arrangements, educational and employment and status, level of social support, asylum status, substance misuse and } \\
\text { presence of clinical mania symptoms. } \\
\text { g. Adjusted as in footnote f, plus use of three pathway contacts. }\end{array}$} \\
\hline
\end{tabular}

of the three contact points was significantly associated with ethnicity. All ethnic groups included in the analysis except South Asians and Black Africans were less likely than White British patients to make contact with a GP within their pathway to care. All groups except Black Africans were more likely to come into contact with emergency medical services, a finding that was particularly strong for Black Caribbeans. All three Black groups underwent higher rates of criminal justice agency involvement in their pathway, and this was especially true of Black African patients.

Some changes to this picture can be seen following adjustment for potential confounders. The excess of contact with primary care in White British patients was no longer statistically significant, particularly in comparison to White Other patients. However, the White British group continued to show higher rates of GP contact in comparison to Black British patients. For involvement of emergency medical services, little change was observed, with the exception that Black Africans were also shown to use this contact more frequently. All Black groups remained more likely to experience criminal justice agency involvement than the White British group, with especially high odds ratios observed in Black Africans and Black Caribbeans.

\section{DUP and pathway contacts}

As ethnic differences were found with regard to both DUP and pathway contacts, the association between these two variables was examined as a post hoc analysis. Results are displayed in Table 4. Both measures of DUP were shown to have a strong positive association with primary care contact and negative association with emergency healthcare contact. Median treatment DUP was more than doubled in those making contact with their GP and halved in those seeking help via emergency medical services. Contact with criminal justice agencies was also significantly associated with a shorter DUP, although this finding appeared somewhat weaker.

\section{Discussion}

This study identifies considerable differences in DUP and the use of pathway contacts between ethnic groups despite the introduction of dedicated services for early psychosis.

\section{Duration of untreated psychosis}

Delays from the onset of psychosis to initiation of pharmacotherapy were longest in White British patients for whom the median value was almost twice that of some BME groups and extended beyond the National Health Service policy target of 3 months. ${ }^{3}$ Delays from the onset of psychosis to referral to early intervention services were overall longer than delays to initiation of drug treatment, suggesting that for many individuals, early intervention service teams do not play a part in the initiation of antipsychotic medication and referral to these services occurs somewhat later. Again, the interval from onset of psychosis to early intervention services referral was longest in White British individuals with an even greater deviation from other ethnic groups. These interesting findings are contrary to much of the existing literature. ${ }^{4,9,17,18}$ Among studies of first-episode psychosis cohorts, only the ÆSOP study $^{6}$ has produced results in this direction, identifying briefer DUP in Black African patients but no other BME group.

\section{Pathway contacts}

Rates of contact with primary care were highest in White British and South Asian patients, with just over half attending the GP practice during their pathway into early intervention services. Adjustment for confounding ameliorated this disparity, with a difference persisting only for Black British patients who were less than two-thirds as likely as White British individuals to visit their GP. Emergency medical services, on the other hand, were more commonly accessed by individuals from BME groups. All three 


\begin{tabular}{|c|c|c|c|c|c|c|c|c|c|}
\hline & \multicolumn{3}{|c|}{ General practitioner } & \multicolumn{3}{|c|}{ Emergency medical services } & \multicolumn{3}{|c|}{ Criminal justice system } \\
\hline & $n(\%)$ & $\begin{array}{l}\text { Odds ratio } \\
(95 \% \mathrm{Cl})\end{array}$ & $P$ & $n(\%)$ & $\begin{array}{l}\text { Odds ratio } \\
(95 \% \mathrm{Cl})\end{array}$ & $P$ & $n(\%)$ & $\begin{array}{l}\text { Odds ratio } \\
(95 \% \mathrm{Cl})\end{array}$ & $P$ \\
\hline White British & $99(54)$ & - & - & $60(33)$ & - & - & $31(17)$ & - & - \\
\hline White Other & $40(39)$ & $\begin{array}{c}0.55(0.34-0.91) \\
0.86^{\mathrm{a}}\end{array}$ & $\begin{array}{l}0.019 \\
0.69^{b}\end{array}$ & $55(54)$ & $\begin{array}{c}2.42(1.47-3.97) \\
4.22^{c}\end{array}$ & $\begin{array}{l}<0.001 \\
<0.001^{\mathrm{C}}\end{array}$ & $23(23)$ & $\begin{array}{c}1.44(0.79-2.63) \\
2.14^{d}\end{array}$ & $\begin{array}{l}0.24 \\
0.11^{d}\end{array}$ \\
\hline South Asian & $41(53)$ & $\begin{array}{c}0.95(0.56-1.62) \\
1.16^{\mathrm{b}}\end{array}$ & $\begin{array}{c}0.85 \\
0.64^{b}\end{array}$ & $40(51)$ & $\begin{array}{c}2.18(1.27-3.74) \\
2.72^{\mathrm{C}}\end{array}$ & $\begin{array}{l}0.005 \\
0.002^{c}\end{array}$ & $12(15)$ & $\begin{array}{c}0.90(0.43-1.86) \\
1.20^{d}\end{array}$ & $\begin{array}{l}0.77 \\
0.66^{d}\end{array}$ \\
\hline Black British & $63(42)$ & $\begin{array}{c}0.62(0.40-0.96) \\
0.60^{\mathrm{b}}\end{array}$ & $\begin{array}{c}0.032 \\
0.029^{b}\end{array}$ & $74(49)$ & $\begin{array}{c}2.01(1.29-3.14) \\
1.97^{c}\end{array}$ & $\begin{array}{l}0.002 \\
0.004^{\mathrm{C}}\end{array}$ & $41(27)$ & $\begin{array}{c}1.86(1.10-3.15) \\
2.15^{\mathrm{d}}\end{array}$ & $\begin{array}{l}0.021 \\
0.007^{d}\end{array}$ \\
\hline Black Caribbean & $7(26)$ & $\begin{array}{c}0.30(0.12-0.75) \\
0.49^{b}\end{array}$ & $\begin{array}{l}0.009 \\
0.24^{b}\end{array}$ & $20(74)$ & $\begin{array}{c}5.91(2.37-14.7) \\
9.94^{\mathrm{C}}\end{array}$ & $\begin{array}{l}<0.001 \\
<0.001^{c}\end{array}$ & $9(33)$ & $\begin{array}{c}2.47(1.02-6.00) \\
4.47^{d}\end{array}$ & $\begin{array}{l}0.046 \\
0.034^{d}\end{array}$ \\
\hline Black African & $60(44)$ & $\begin{array}{c}0.69(0.44-1.07) \\
1.39^{b}\end{array}$ & $\begin{array}{l}0.099 \\
0.47^{b}\end{array}$ & $58(43)$ & $\begin{array}{c}1.56(0.98-2.47) \\
2.99^{C}\end{array}$ & $\begin{array}{l}0.059 \\
0.018^{c}\end{array}$ & $48(36)$ & $\begin{array}{c}2.72(1.62-4.59) \\
4.03^{d}\end{array}$ & $\begin{array}{r}<0.001 \\
0.012^{d}\end{array}$ \\
\hline $\begin{array}{l}\text { a. SPSS } 17.0 \text { unable } \\
\text { b. Adjusted for age, } \\
\text { presence of clinical } \\
\text { c. Adjusted for age, } \\
\text { Scale total score. } \\
\text { d. Adjusted for age, } \\
\text { insight and presenc }\end{array}$ & $\begin{array}{l}\text { nerate odd } \\
\text { er, marital } \\
\text { a symptom } \\
\text { er, marital } \\
\text { er, marital } \\
\text { linical man }\end{array}$ & $\begin{array}{l}\text { tio confidence interva } \\
\text { us, having children, U } \\
\text { us, UK birth, living arr } \\
\text { us, having children, U } \\
\text { /mptoms. }\end{array}$ & $\begin{array}{l}\text { S for pool } \\
\text { birth, livi } \\
\text { ngements } \\
\text { birth, livi }\end{array}$ & $\begin{array}{l}\text { stic regres } \\
\text { angements } \\
\text { ational stat } \\
\text { angements }\end{array}$ & $\begin{array}{l}\text { analyses derived fro } \\
\text { social support, asylu }\end{array}$ & $\begin{array}{l}\text { m imputed d } \\
\text { al support, as } \\
\text { m status, sub } \\
\text { ment status, }\end{array}$ & $\begin{array}{l}\text { ets. } \\
\text { n status, s } \\
\text { ce misuse } \\
\text { al support }\end{array}$ & $\begin{array}{l}\text { stance misuse, insigh } \\
\text { hd Positive and Nega } \\
\text { sylum status, substan }\end{array}$ & $\begin{array}{l}\text { d } \\
\text { Syndrome } \\
\text { misuse, }\end{array}$ \\
\hline
\end{tabular}

Black groups appeared more likely than White British individuals to make contact with early intervention services via criminal justice agencies and after adjustment for confounding, the magnitude of this difference for first-generation individuals was more than fivefold. These findings are more familiar. Perhaps the most relevant comparator, the ÆSOP study, showed similar disparities regarding GP and criminal justice agency contact between Black and White individuals. Looking beyond studies restricted to early psychosis, a finding of higher rates of GP attendance in South Asians for psychiatric ${ }^{19}$ and general complaints $^{20}$ was not replicated here, with this group showing similar use of primary care to White British patients.

Almost a quarter of individuals made contact with the criminal justice system as part of their pathway to care and this is comparable to findings of the ÆSOP study. Increased involvement of these agencies for Black patients is frequently ${ }^{8}$ but not consistently reported in the literature; ${ }^{21}$ a finding that cannot be explained by differential rates of police contact across ethnic groups in the general population. A household survey ${ }^{22}$ exploring offending behaviour and contact with the criminal justice system in individuals from 10 to 65 years of age in England and Wales showed that Black individuals were no more likely to have ever been arrested or convicted. They did however show higher rates of detention into custody. Interestingly, South Asians showed very low rates of criminality and contact with the police in this study.

\section{Explaining the findings}

With regard to overall length of DUP, comparing our findings with previous papers, ${ }^{17,23,24}$ our post hoc findings that GP attendance is associated with prolonged DUP, and emergency medical services and criminal justice agency contact with briefer DUP, may help us to theorise about the mechanism for treatment delays in White British patients. Slower referral from primary care might be explained in two main ways. First, it may be that GPs see less acute and apparently risky presentations, reflected in greater delays in families seeking help and in less tendency to initiate medication urgently and, if necessary, coercively following first presentation to health services. Second, aspects of GPs' approach and knowledge may result in delays: they may as yet lack the skills to recognise early psychosis or if they do, may be uncertain how to approach the many young people with first-episode psychosis who decline most help and are resistant to referral to mental health services. ${ }^{25}$

With regard to the unanticipated difference in DUP between ethnic groups, its persistence despite adjusting for a range of social and clinical potential confounders suggests that differences in pathway to care may well contribute substantially, with the tendency of White British patients to seek help via GPs ultimately contributing to a longer DUP. Potential reasons for this pattern of help-seeking include greater likelihood of being registered with a GP, greater use of and trust in primary care services, and greater inclination among White British people to understand the symptoms of psychosis in terms of mental ill health. Young Black British men tend to show high levels of dissatisfaction with most aspects of mental health services, ${ }^{26}$ often viewing them as simply another branch of the criminal justice system. ${ }^{27}$ Avoidance by the person with psychosis and their family of a service that they perceive to be unnecessary, unhelpful or discriminatory may result in delays in presentation until a crisis emerges. This is supported by research in Black groups showing that patients do indeed tend to present in crisis when they are more likely to be seen by the duty psychiatrist in the accident and emergency department. ${ }^{17,18}$

\begin{tabular}{|c|c|c|c|c|c|c|c|c|c|c|c|c|}
\hline & \multicolumn{4}{|c|}{ General practitioner } & \multicolumn{4}{|c|}{ Emergency medical services } & \multicolumn{4}{|c|}{ Criminal justice system } \\
\hline & No & Yes & $t$ (d.f.) & $P^{\mathrm{a}}$ & No & Yes & $t(\text { d.f. })^{a}$ & $P^{\mathrm{a}}$ & No & Yes & $t(\text { d.f. })^{a}$ & $P^{\mathrm{a}}$ \\
\hline Treatment DUP & 7.3 & 16.2 & $-5.11(509)$ & $<0.001$ & 15.2 & 7.1 & $5.09(491)$ & $<0.001$ & 12.8 & 10.1 & $2.33(509)$ & 0.020 \\
\hline Service DUP & 12.0 & 23.0 & $-5.31(567)$ & $<0.001$ & 20.9 & 12.0 & $4.05(567)$ & $<0.001$ & 17.5 & 13.6 & $2.26(567)$ & 0.024 \\
\hline
\end{tabular}


Furthermore, their family and friends are more likely to seek help directly from the police than those of other ethnic groups. ${ }^{7,28}$

Other possible explanations for these differences relate to ethnic variations in the clinical presentation of psychotic illness or to clinicians' responses to it. Mode of psychosis onset, as a variable, tends to plague studies exploring DUP as its insidious form has been shown to be associated with prolonged DUP and may therefore exert a confounding effect. ${ }^{29,30}$ A propensity for White British patients to undergo a more insidious illness onset or a protracted prodrome must therefore also be considered as a possible explanation for differences in DUP. However, a small study finding similar modes of onset across ethnic groups provides some evidence against this. ${ }^{31}$

\section{Implications}

Across all ethnic groups, a striking finding is that there is little evidence that early intervention service introduction has had a substantial effect either on DUP or on routes into services. Long delays in obtaining potentially effective treatment are still frequent, and many access services via emergency or criminal justice services. This lack of impact is not a great surprise given that many services appear to focus primarily on improving social recovery and preventing relapse once patients have entered services, often beginning their active work with patients only as they are discharged from an episode of acute care. ${ }^{10}$ Thus, further service development is required if the original aspiration for these services of reducing DUP and promoting non-coercieve community-based pathways into care is to be achieved. How might this be done? This paper indicates ethnic differences in the challenges to be addressed.

For White British patients, reducing delays currently encountered in pathways via primary care is central. An obvious strategy might be education and promotion of prompt referral from GPs. However, studies thus far suggest little effect from early detection strategies focusing on primary care. ${ }^{32-34}$ This may be due to the difficulties in identifying psychosis at an early stage ${ }^{35}$ and the limited willingness and capacity of primary care professionals with large case-loads to spend time seeking to engage people who resist assessment of their mental health. Considering alternative strategies for early detection, the only type of initiative to have demonstrated effectiveness in at least some settings is public education campaigns accompanied by direct access to specialist services for people with incipient psychosis and their carers. Our findings regarding long delays in access via primary care lend weight to the idea that such public health campaigns may be the best prospect for reducing DUP.

For the Black ethnic groups investigated in this study, the most prominent challenge is not so much shortening DUP but reducing coercive routes to services that may well contribute to subsequent high rates of disengagement from services and compulsory treatment. ${ }^{36}$ Again, we need to consider what alternative pathways into services might realistically divert people from these routes. Primary care is still a less plausible focus than for the White British group, given that patients from these backgrounds tend not to be seeking help from any health service prior to crisis point. Some form of public education and direct access to services ${ }^{34}$ again seems the most plausible potential route, but the challenges are considerable given the low rates of seeking any healthcare. Public education campaigns which focus on the explanatory models of illness and help-seeking patterns of particular minorities appear the most promising focus.

Thus, while obstacles to prompt treatment and a benign first experience of mental healthcare appear to vary across ethnic groups, in each case some form of initiative providing education and direct access to services to the public seems the most feasible approach. This has previously shown benefits, ${ }^{34}$ but so far only from studies where it has been very intensively implemented with most people in the study areas likely to be repeatedly exposed to messages about psychosis, and in areas without great ethnic diversity. The challenge is to find cost-effective ways of doing this without unjustifiable expenditure and with reach across a reasonable range of groups. Social media may hold a key to achieving this, and it may be that generic youth mental health services, with less pressure to identify psychosis specifically, are better placed to engage people with early psychosis. Furthermore, once psychotic symptoms are identified it would seem more appropriate to focus on getting people into early intervention services faster rather than simply handing out antipsychotics earlier. This is important in order to ensure that individuals whose symptoms may resolve quickly do not receive unnecessary medications that in some cases produce harmful side-effects and may have a negative impact on engagement.

\section{Limitations}

Although the pragmatic approach taken in this study and the use of a large number of patients from a range of early intervention services allows us to feel more confident that these are real-world findings, there are a number of potential limitations.

(a) Selection bias - although some services collected data regarding each consecutive referral meeting the entry criteria for early intervention services, this was not performed uniformly.

(b) Sampling issues - there were insufficient numbers to examine South Asian ethnic groups separately and data were drawn mainly from inner-city areas. This limits the generalisability of the results.

(c) Measurement bias - data regarding onset of psychosis and the pathway to care were collected retrospectively and therefore prone to recall bias. Definitions and measurements of ethnicity and DUP are especially complex, limiting reliability of clinician recording and direct comparability across studies.

(d) Missing data bias - although statistically managed using multiple imputation for regression analyses, the variability of data completeness remains an inevitable disadvantage of the naturalistic methodology.

Sharif Ghali, MRCPsych, MSC, Berkshire Healthcare NHS Foundation Trust; Helen L. Fisher, PhD, MRC SGDP Centre, Institute of Psychiatry, King's College London; John Joyce, MRCPsych, Lewisham Early Intervention Service, South London and Maudsley NHS Foundation Trust; Barnaby Major, MRCPsych, MSc, East London NHS Foundation Trust; Lorna Hobbs, BPSySC, Sujata Soni, MSc, Department of Mental Foundation Trust; Lorna Hobbs, BPSySc, Sujata Soni, MSc, Department of
Health Sciences, University College London; Brock Chisholm, DClinPsych, Wandsworth Early Intervention Service, Southwest London \& St Georges' Mental Heath NHS Trust; Nikola Rahaman, MRCPsych, Peggy Papada, MA, Kensington, Chelsea, Westminster \& Brent Early Intervention Service, Central \& North West London NHS Foundation Trust; Jo Lawrence, MSC, STEP, Southwark, South London and Maudsley NHS Foundation Trust; Sally Bloy, MSC, Psychological Medicine, Institute of Psychiatry, King's College London; Karl Marlowe, MSc, MRCPsych, Tower Institute of Psychiatry, King's College London; Karl Marlowe, MSc, MRCPSych,
Hamlets, East London NHS Foundation Trust; Katherine J. Aitchison, PhD, FRCPsych, Department of Psychiatry, University of Alberta, Canada, and MRC SGDP Centre, Institute of Psychiatry, King's College London, and COAST, South London and Maudsley NHS Foundation Trust; Paddy Power, MD, Department of Psychological Medicine, Institute of Psychiatry, King's College London; Sonia Johnson DM, Department of Mental Health Sciences, University College London, and Early Intervention Service, Camden and Islington NHS Foundation Trust, UK

Correspondence: Sharif Ghali, Prospect Park Hospital, Honey End Lane, Reading, Berkshire RG30 4EJ, UK. Email: sharifghali@doctors.org.uk

First received 23 Jun 2011, final revision 31 May 2012, accepted 23 Jul 2012

\section{Funding}

This work was supported by the London Development Centre for Mental Health. Initial pilot work within Camden \& Islington early intervention services was supported by Islington 
Primary Care Trust. These funding bodies had no further role in study design, in the collection, analysis and interpretation of data, in the writing of the report and in the decision to submit the paper for publication. K.J.A. holds an Alberta Centennial Addiction and Mental Health Research Chair, funded by the Government of Alberta.

\section{Acknowledgements}

We are extremely grateful to clinicians and patients from the participating teams for their time and enthusiasm. We would particularly like to acknowledge the contributions of Kate Theodore, Tom Grange, Katharine McLoughlin, Kelso Cratsley, Laurence Church, Rhianne Doherty, Sasha Gold, Denise Bevan, Lisa Gaiotto, Peter Bailey, Jana Advani, Teuta Rexhepi, Charlie Heriot-Maitland and Mima Simic to collection of data in the individual sites. Thanks also to members of LEIRN, especially Swaran Singh, Aurelie Freeman, Maxine Sacks, Gillian Paul, Emma Stinton and Jim O'Donnell for their contributions to the development and implementation of the package.

\section{References}

1 Singh SP, Fisher HL. Early intervention services. Psychiatry 2007; 6: 333-8.

2 Marshall M, Lewis S, Lockwood A, Drake R, Jones $\mathrm{P}$, Croudace $\mathrm{T}$. Association between duration of untreated psychosis and outcome in cohorts of first-episode patients: a systematic review. Arch Gen Psychiatry 2005; 62: 975-83.

3 Department of Health. Improvement, Expansion and Reform: The Next 3 Years. Priorities and Planning Framework 2003-2006. Department of Health 2002.

4 Bechard-Evans L, Schmitz N, Abadi S, Joober R, King S, Malla A. Determinants of help-seeking and system related components of delay in the treatment of first-episode psychosis. Schizophr Res 2007; 96: 206-14.

5 Sohler NL, Bromet EJ, Lavelle J, Craig TJ, Mojtabai R. Are there racial differences in the way patients with psychotic disorders are treated at their first hospitalization? Psychol Med 2004; 34: 705-18.

6 Morgan C, Fearon P, Hutchinson G, McKenzie K, Lappin JM, Abdul-Al R, et al. Duration of untreated psychosis and ethnicity in the AESOP first-onset psychosis study. Psychol Med 2005; 36: 239-47.

7 Morgan C, Mallett R, Hutchinson G, Bagalkote H, Morgan K, Fearon P, et al. Pathways to care and ethnicity. 2: Source of referral and help-seeking Report from the AESOP study. Br J Psychiatry 2005; 186: 290-6.

8 Bhui K, Stansfeld S, Hull S, Priebe S, Mole F, Feder G. Ethnic variations in pathways to and use of specialist mental health services in the UK: systematic review. Br J Psychiatry 2003; 182: 105-16.

9 Archie S, Akhtar-Danesh N, Norman R, Malla A, Roy P, Zipursky RB. Ethnic diversity and pathways to care for a first episode of psychosis in Ontario. Schizophr Bull 2010; 36: 688.

10 Fisher $\mathrm{H}$, Theodore $\mathrm{K}$, Power $\mathrm{P}$, Chisholm B, Fuller J, Marlowe $\mathrm{K}$, et al. Routine evaluation in first episode psychosis services: feasibility and results from the MiData project. Soc Psychiatry Psychiatr Epidemiol 2008; 43: 960-7.

11 Singh SP, Cooper JE, Fisher HL, Tarrant CJ, Lloyd T, Banjo J, et al. Determining the chronology and components of psychosis onset: The Nottingham Onset Schedule (NOS). Schizophr Res 2005; 80: 117-30.

12 Kay SR, Fiszbein A, Opler LA. The positive and negative syndrome scale (PANSS) for schizophrenia. Schizophr Bull 1987; 13: 261-76.

13 Office for National Statistics. 2001 Census for England and Wales. ONS.

14 Young RC, Biggs JT, Ziegler VE, Meyer DA. A rating scale for mania: reliability, validity and sensitivity. Br J Psychiatry 1978; 133: 429-35

15 Endicott J, Spitzer RL, Fleiss JL, Cohen J. The global assessment scale. A procedure for measuring overall severity of psychiatric disturbance. Arch Gen Psychiatry 1976; 33: 766-71.
16 Drake RE, Wallach MA. Substance abuse among the chronic mentally ill. Hosp Community Psychiatry 1989; 40: 1041-6.

17 Cole E, Leavey G, King M, Johnson-Sabine E, Hoar A. Pathways to care for patients with a first episode of psychosis. A comparison of ethnic groups. Br J Psychiatry 1995; 167: 770-6.

18 Turner M, Smith-Hamel C, Mulder R. Pathways to care in a New Zealand first episode of psychosis cohort. Aust N Z J Psychiatry 2006; 40: 421-8.

19 Commander MJ, Dharan SP, Odell SM, Surtees PG. Access to mental health care in an inner-city health district. I: Pathways into and within specialist psychiatric services. Br J Psychiatry 1997; 170: 312-6.

20 Gillam SJ, Jarman B, White P, Law R. Ethnic differences in consultation rates in urban general practice. BMJ 1989; 299: 953.

21 Moodley $P$, Perkins RE. Routes to psychiatric inpatient care in an Inner London Borough. Soc Psychiatry Psychiatr Epidemiol 1991; 26: 47-51.

22 Sharp C, Budd T. Minority Ethnic Groups and Crime: Findings from the Offending, Crime and Justice Survey 2003. Home Office, 2005.

23 Burnett R, Mallett R, Bhugra D, Hutchinson G, Der G, Leff J. The first contact of patients with schizophrenia with psychiatric services: social factors and pathways to care in a multi-ethnic population. Psychol Med 1999; 29 : 475-83.

24 Skeate A, Jackson C, Birchwood M, Jones C. Duration of untreated psychosis and pathways to care in first-episode psychosis: investigation of help-seeking behaviour in primary care. Br J Psychiatry 2002; 181 (suppl 43): s73-7.

25 EL Adl M, Burke J, Little K. First-episode psychosis: primary care experience and implications for service development. Psychiatr Bull 2009; 33: 165-8.

26 Parkman S, Davies S, Leese M, Phelan M, Thornicroft G. Ethnic differences in satisfaction with mental health services among representative people with psychosis in south London: PRiSM study 4. Br J Psychiatry 1997; 171: 260-4.

27 Appleby L. Services for ethnic minorities: a question of trust. Psychiatr Bull 2008; 32: 401-2.

28 Owens D, Harrison G, Boot D. Ethnic factors in voluntary and compulsory admissions. Psychol Med 1991; 21: 185-96.

29 Norman RMG, Malla AK. Duration of untreated psychosis: a critical examination of the concept and its importance. Psychol Med 2001; 31: 381-400.

30 Morgan C, Abdul-Al R, Lappin JM, Jones P, Fearon P, Leese M, et al. Clinical and social determinants of duration of untreated psychosis in the ÆESOP first-episode psychosis study. Br J Psychiatry 2006; 189: 446-52.

31 King $M$, Coker E, Leavey G, Hoare A, Johnson-Sabine E. Incidence of psychotic illness in London: comparison of ethnic groups. BMJ 1994; 309: 1115-9.

32 Power P, lacoponi E, Reynolds N, Fisher H, Russell M, Garety PA, et al. The Lambeth Early Onset Crisis Assessment Team Study: general practitioner education and access to an early detection team in first-episode psychosis. Br J Psychiatry 2007; 191 (suppl 51): s133-9.

33 Lester H, Birchwood M, Freemantle N, Michail M, Tait L. REDIRECT: cluster randomised controlled trial of GP training in first-episode psychosis. $\mathrm{Br} J \mathrm{Gen}$ Pract 2009; 59: e183-90.

34 Lloyd-Evans B, Crosby M, Stockton S, Pilling S, Hobbs L, Hinton M, Johnson S. Initiatives to shorten duration of untreated psychosis: systematic review. Br J Psychiatry 2011; 198: 256-63.

35 Tanskanen S, Morant N, Hinton M, Lloyd-Evans B, Crosby M, Killaspy H, et al. Service user and carer experiences of seeking help for a first episode of psychosis: a UK qualitative study. BMC Psychiatry 2011; 11: 157.

36 Lawlor C, Johnson S, Cole L, Howard LM. Ethnic variations in pathways to acute care and compulsory detention for women experiencing a mental health crisis. Int J Soc Psychiatry 2012; 58: 3-15. 